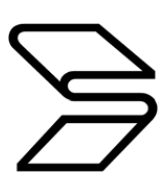





\title{
Sprachen der Welt
}

Ein weltweiter Index der Sprachfamilien, Einzelsprachen und Dialekte, mit Angabe der Synonyma

und fremdsprachigen Äquivalente

Zweite überarbeitete und erweiterte Ausgabe

\section{Languages of the World}

\author{
A Multi-lingual Concordance \\ of Languages, Dialects \\ and Language-Families
}

Second revised and enlarged Edition 
Ob fugam vacui

(Josef Nadler; Johann George Hamann 1949)

Die Deutsche Bibliothek - CIP-Einheitsaufnahme

Klose, Albrecht:

Sprachen der Welt : ein weltweiter Index

der Sprachfamilien, Einzelsprachen und Dialekte, mit Angabe der Synonyma

und fremdsprachigen Äquivalente

$=$ Languages of the world / Albrecht Klose.

- 2., überarb. und erw. Ausg..

- München: Saur, 2001

ISBN 3-598-11404-4

(a)

Gedruckt auf säurefreiem Papier / Printed on acid-free paper

Alle Rechte vorbehalten / All Rights Strictly Reserved

K.G. Saur Verlag GmbH München 2001

Printed in the Federal Republic of Germany

Jede Art der Veröffentlichung ohne Erlaubnis des Verlags ist unzulässig

Satz / Typesetting: bsix - information exchange GmbH, Braunschweig

Druck / Printing: Strauss Offsetdruck, Mörlenbach

Binden / Binding: Buchbinderei Schaumann, Darmstadt

ISBN 3-598-11404-4 